\title{
Safety, pharmacokinetics, and pharmacodynamic properties of oral DEBIO1143 (AT-406) in patients with advanced cancer: results of a first-in-man study
}

\author{
Herbert I. Hurwitz · David C. Smith $\cdot$ Henry C. Pitot $\cdot$ Jeffrey M. Brill $\cdot$ \\ Rashmi Chugh · Elisabeth Rouits · Joseph Rubin · John Strickler • \\ Gregoire Vuagniaux · J. Mel Sorensen · Claudio Zanna
}

Received: 18 August 2014 / Accepted: 14 February 2015 / Published online: 27 February 2015

(C) The Author(s) 2015. This article is published with open access at Springerlink.com

\begin{abstract}
Purpose To assess safety/tolerability, pharmacokinetics (PK), pharmacodynamics (PD), and antitumor activity of DEBIO1143, an antagonist of inhibitor apoptosis proteins.

Methods This first-in-man study in patients with advanced cancer used an accelerated dose titration design. DEBIO1143 was given orally once daily on days 1-5 every 2 or 3 weeks until disease progressed or patients dropped out. The starting dose of $5 \mathrm{mg}$ was escalated by $100 \%$ in single patients until related grade 2 toxicity occurred. This triggered expansion to cohorts of three and subsequently six patients and reduction in dose increments to $50 \%$. Maximum tolerated dose (MTD) was exceeded when any two patients within the same cohort experienced dose-limiting toxicity (DLT). On days 1 and 5, PK and PD samples were taken.
\end{abstract}

ClinicalTrials.gov identifier: NCT01078649.

Electronic supplementary material The online version of this article (doi:10.1007/s00280-015-2709-8) contains supplementary material, which is available to authorized users.

\author{
H. I. Hurwitz $(\bowtie) \cdot$ J. Strickler \\ Department of Medicine, Duke University School of Medicine, \\ DUMC 3052, Durham, NC 27710, USA \\ e-mail: herbert.hurwitz@duke.edu \\ D. C. Smith $\cdot$ R. Chugh \\ University of Michigan, Ann Arbor, MI, USA \\ H. C. Pitot · J. Rubin \\ Mayo Clinic, Rochester, MN, USA \\ J. M. Brill · J. M. Sorensen \\ Ascenta Therapeutics, Malvern, PA, USA \\ E. Rouits $\cdot$ G. Vuagniaux $\cdot$ C. Zanna \\ Debiopharm International SA, Lausanne, Switzerland
}

Results Thirty-one patients received doses from 5 to $900 \mathrm{mg}$. Only one DLT was reported at $180 \mathrm{mg}$. No MTD was found. Most common adverse drug reactions were fatigue $(26 \%)$, nausea $(23 \%)$, and vomiting (13\%). Average $t_{\max }$ and $T_{1 / 2}$ was about 1 and $6 \mathrm{~h}$, respectively. Exposure increased proportionally with doses from 80 to $900 \mathrm{mg}$, without accumulation over 5 days. Plasma CCL2 increased at 3-6 h postdose and epithelial apoptosis marker M30 on day 5; cIAP-1 levels in PBMCs decreased at all doses $>80 \mathrm{mg}$. Five patients $(17 \%)$ had stable disease as the best treatment response.

Conclusion DEBIO1143 was well tolerated at doses up to $900 \mathrm{mg}$ and elicited PD effects at doses greater $80 \mathrm{mg}$. Limited antitumor activity may suggest development rather as adjunct treatment.

Keywords IAP · Apoptosis · AT-406 - DEBIO1143 · Cancer $\cdot$ Resistance

\section{Introduction}

Inhibitors of apoptosis proteins (IAPs) may play a role in the development of cancer [1,2]. Their over-expression has been linked not only to tumor growth and poor prognosis, but also to low treatment response or resistance [2, 4]. Therefore, the IAP protein family is generally considered a promising target for cancer drug development $[2,5,6]$. So far, six IAP antagonists have entered clinical development [3]. One of these is DEBIO1143 (formerly AT-406, SM-406), a small molecule mimetic of second mitochondria-derived activator of caspase (SMAC) [7].

In vitro studies have demonstrated DEBIO1143 to inhibit cell growth in various human cancer cell lines [2, 4] through binding of X-chromosome-linked IAP (XIAP) and 
cellular IAPs 1 and 2 (cIAP-1 and -2). DEBIO1143 rapidly induced degradation of cIAP-1 in a cell-free functional assay [7] and apoptosis in xenograft tumors. Moreover, it was able to enhance the antitumoral effects of irradiation or various chemotherapeutic agents in multiple mouse cancer models $[1,4,8]$. Preclinical data further revealed good oral bioavailability in mice, rats, dogs, and non-human primates, enabling PK/PD modeling to predict tumor and plasma concentrations in humans [1].

Multiple high doses (40-120 mg/kg/day) induced hepatotoxicity in rats. In dogs, liver cell degeneration was seen at 3 and $10 \mathrm{mg} / \mathrm{kg} /$ day. In 4-week toxicology studies, the severely toxic dose (STD) in the rat was determined at $40 \mathrm{mg} / \mathrm{kg}$ and the highest non-severely toxic dose (HNSTD) in a non-rodent species at $1 \mathrm{mg} / \mathrm{kg}$ in dogs. Based on metabolism data and observed adverse events (AEs), the dog was considered the most relevant species, in line with reports on other IAP inhibitors [9]. The no observable adverse event level (NOAEL) of $1 \mathrm{mg} / \mathrm{kg}$ in dogs led to a calculated starting dose of $5 \mathrm{mg}$ in humans. An intermittent dosing schedule was chosen to further mitigate the risk of unacceptable toxicity when entering clinical development.

The primary objective of this first-in-man study was to characterize the safety and determine the maximum tolerated dose (MTD) and schedule of DEBIO1143 when administered to patients with advanced solid tumors and lymphomas. Secondary objectives were to explore (a) PK of DEBIO1143, (b) any PD effects, (c) any observable antitumor activity during the trial, and (d) its correlation with PK.

\section{Materials and methods}

\section{Design}

This was a multicenter, uncontrolled, open-label, doseescalation study on DEBIO1143 in patients with advanced cancer. It employed an accelerated titration design for dose escalation with $100 \%$ dose increments in consecutively enrolled single patients until drug-related grade- 2 toxicity was observed during the initial treatment cycle (until day 28 or day 21 as per protocol amendment). If this was the case, cohort size was expanded to three patients and dosing increment was reduced to $50 \%$ of the last dose. Dose escalation was to be stopped at the MTD which was considered exceeded if at any dose level more than one patient experienced dose-limiting toxicity (DLT) during the first treatment cycle. DLT was defined as any of the following: (a) non-hematological toxicity of grade $\geq 3$ (excluding nausea, vomiting, diarrhea unless not controlled by maximal antiemetic/diarrheal therapy for $>24 \mathrm{~h}$ ); (b) anemia or neutropenia of grade $\geq 3$ or thrombocytopenia of grade 4 or any grade if associated with clinically significant bleeding; (c) any AE resulting in dose delay or reduction; (d) any toxicity considered dose-limiting by the investigator. If only one out of the three patients of a cohort experienced drugrelated DLT, the cohort was expanded by another three patients to be treated at the same dose level. If none of these additional patients experienced DLT, the dose escalation by $50 \%$, rounded down to the nearest capsule strength combination, continued in the next cohort of three patients.

Pharmacokinetic samples were taken from all patients on day 1 (predose, $0.5,1,2,3,4,6,8,12,18 \mathrm{~h}$ postdose) and on day 5 (predose, 0.5, 1, 2, 3, 4, 6, $8 \mathrm{~h}$ postdose) of the first cycle. In addition, for exploratory PD analysis of IAP inhibition and activation of apoptosis, optional skin and tumor biopsies were taken from consenting patients on days 1 (predose) and 5 and blood samples on day 1 (predose, $1,3,6,8,12 \mathrm{~h}$ postdose), day 2 (predose), and day 5 ( $3 \mathrm{~h}$ postdose).

The study was compliant with all applicable legal obligations, the requirements of the Declaration of Helsinki and Good Clinical Practice. It was approved by the institutional review boards of the three participating sites and registered under Clinicaltrials.gov (identifier: NCT01078649).

\section{Patient population}

Eligible were male and female adult outpatients with histologically confirmed advanced or metastatic solid tumors or lymphoma for which no life prolonging or appropriate standard therapy was available. Patients had to be ambulatory (Eastern Cooperative Oncology Group (ECOG) performance status $\leq 1$ ) with adequate hematological (ANC $\geq 1,500 / \mathrm{mm}^{3}$; hemoglobin $>9.0 \mathrm{~g} / \mathrm{dL}$; platelet count $\geq 100,000 / \mathrm{mm}^{3}$ ), renal (creatinine $\leq 1.0 \times$ upper limit of normal (ULN) or creatinine clearance of $>60 \mathrm{ml} /$ $\min$ ), hepatic (serum albumin $\geq 3.0 \mathrm{gm} / \mathrm{dL}$; total bilirubin $<1.0 \times \mathrm{ULN}$; aminotransferases and alkaline phosphatase $\leq 2.5 \times$ ULN, including negative hepatitis testing), and cardiac function without evidence of QTc prolongation.

As clinically significant bleeding formed part of the definition of DLT, further exclusion criteria were a history of gastrointestinal bleeding during the preceding year, of treatment-requiring diabetes mellitus, or any condition associated with chronic inflammation (e.g., rheumatoid arthritis, inflammatory bowel disease, chronic infections) or affecting copper accumulation or regulation (e.g., Wilson's disease).

Last radiation and intake of steroids had to date back at least 14 days from study entry (thoracic radiation 28 days); patients had to be clinically stable and to have recovered to toxicity grade $\leq 1$ from any prior cancer therapy. Patients had to have never received IAP inhibitors before. All patients had to give written informed consent to be enrolled in the trial. 


\section{Treatment}

Oral treatment had to be taken daily on days $1-5$, initially every 14 days, later every 21 days as per protocol amendment. The amendment was put in place to be more conducive to future combination with common chemotherapy regimens and to reduce the potential for adverse drug reactions (ADRs) through an additional week of recovery between doses. The starting dose of $5 \mathrm{mg}$ was increased in subsequent cohorts, based on DLT observed by the end of cycle 1. Stable or responding patients who experienced DLT were allowed to continue therapy at the next lower dose, once those had resolved to grade $\leq 1$ within 2 weeks. End of treatment was triggered by disease progression, unacceptable toxicity, or withdrawal from the study for any reason. Cancer therapy other than DEBIO1143 was not allowed, but supportive care measures were. Concomitant treatment with aspirin at doses $>81 \mathrm{mg} /$ day or with any anticoagulants was prohibited.

\section{Endpoints}

\section{Safety}

The incidence of AE, ADR, and DLT was recorded at all scheduled visits (on days 1, 15, and 28 of each cycle and additionally on days 5,8 , and 22 of cycle 1) and graded according to the Common Terminology Criteria for Adverse Events, version 4.0 of the National Cancer Institute. Moreover, safety laboratory, 12-lead ECG, vital sign measurements, and physical examinations were performed.

\section{Pharmacokinetics}

$C_{\max }$ and $t_{\max }$ were determined by direct assessment of the observed concentration versus time curves. The area under the curve until the last quantifiable concentration $\left(\mathrm{AUC}_{0-\mathrm{t}}\right)$ was estimated by a linear up/log down method if $\geq 3$ values were available and extrapolated to infinity ( $\mathrm{AUC}_{\text {inf }}$ ), if the extrapolated part was $<30 \%$. The terminal elimination half-life $\left(T_{1 / 2}\right)$ was calculated as the ratio of $\log _{\mathrm{e}}^{2}$ to the apparent terminal phase rate constant $\left(\lambda_{\mathrm{z}}\right)$, determined through unweighted linear regression analysis on $\geq 3$ logtransformed concentrations on the linear portion of the terminal slope, excluding the peak concentration. In general, points maximizing $R^{2}$ up to at least 0.9 were included for linear regression.

\section{Pharmacodynamics}

cIAP-1 levels were measured in tumor tissue and surrogate tissue as available. Peripheral blood mononuclear cells (PBMCs) were analyzed for DEBIO1143-induced cIAP-1 degradation. Plasma native cytokeratin-18 (M65) or caspase-3 generated cytokeratin-18 fragments (M30), interleukin 8 (IL8), chemokine ligand 2 (CCL2, MCP1), and tumor necrosis factor $\alpha(\mathrm{TNF} \alpha)$ were measured by ELISA as markers of epithelial cell death and inflammation on days 1 (predose, 1, 3, 6, and $12 \mathrm{~h}$ postdose), 2, and 5 .

\section{Efficacy}

Tumor evaluations were scheduled before therapy and after every other cycle of therapy. Changes were determined by physical examination, tumor markers, or standard imaging techniques. Response to DEBIO1143 was assessed for solid tumors based on RECIST guidelines, version 1.1 [10] and for lymphoma as per the Revised Response Criteria for Malignant Lymphoma [11]. Read-outs were complete response $(\mathrm{CR})$, partial response $(\mathrm{PR})$, stable disease $(\mathrm{SD})$, and disease progression (DP).

PK and PD analyses

DEBIO1143 plasma concentrations were measured using a validated LC-MS/MS assay. For the detection of cIAP-1 in paraffin-embedded human tissue, a validated immunohistochemical (IHC) assay was used. DEBIO1143-induced cIAP-1 degradation was measured in PBMCs using Western blot. Plasma biomarkers were measured through commercial ELISAs. All laboratory analyses were performed by MPI Research, Inc. (PK) and Mosaic Laboratory, LLC (PD).

Data analysis

Descriptive statistics were presented as appropriate. Safety laboratory assessments, vital signs, body weight, ECOG, ECG, as well as PD and tumor response data were compared over time to assess change from baseline during treatment and follow-up. In case of sufficient sample size, Wilcoxon matched pairs test was used for inferential comparisons. Data were analyzed using the Statistical Analysis System (SAS), version 9.1.3. Individual PK parameters were derived using WinNonlin (version 5.3, Pharsight Corp., Mountain View, CA).

\section{Results}

From March 30, 2010, until August 8, 2012, 31 patients, 12 men $(38.7 \%)$ and 19 women $(61.3 \%)$ with a mean age of $52 \pm 11$ years, were enrolled and treated in 11 cohorts with oral DEBIO1143 doses ranging from 5 to $900 \mathrm{mg}$ (5, 10, 20, 40, 80, 120, 180, 260, 400, 600, 900 mg; Fig. 1). The great majority of patients were Caucasians $(87.1 \%$; 
Fig. 1 Patient flowchart according to CONSORT. $D P$ disease progression (second line: duration of stable disease); UPR upon patient request

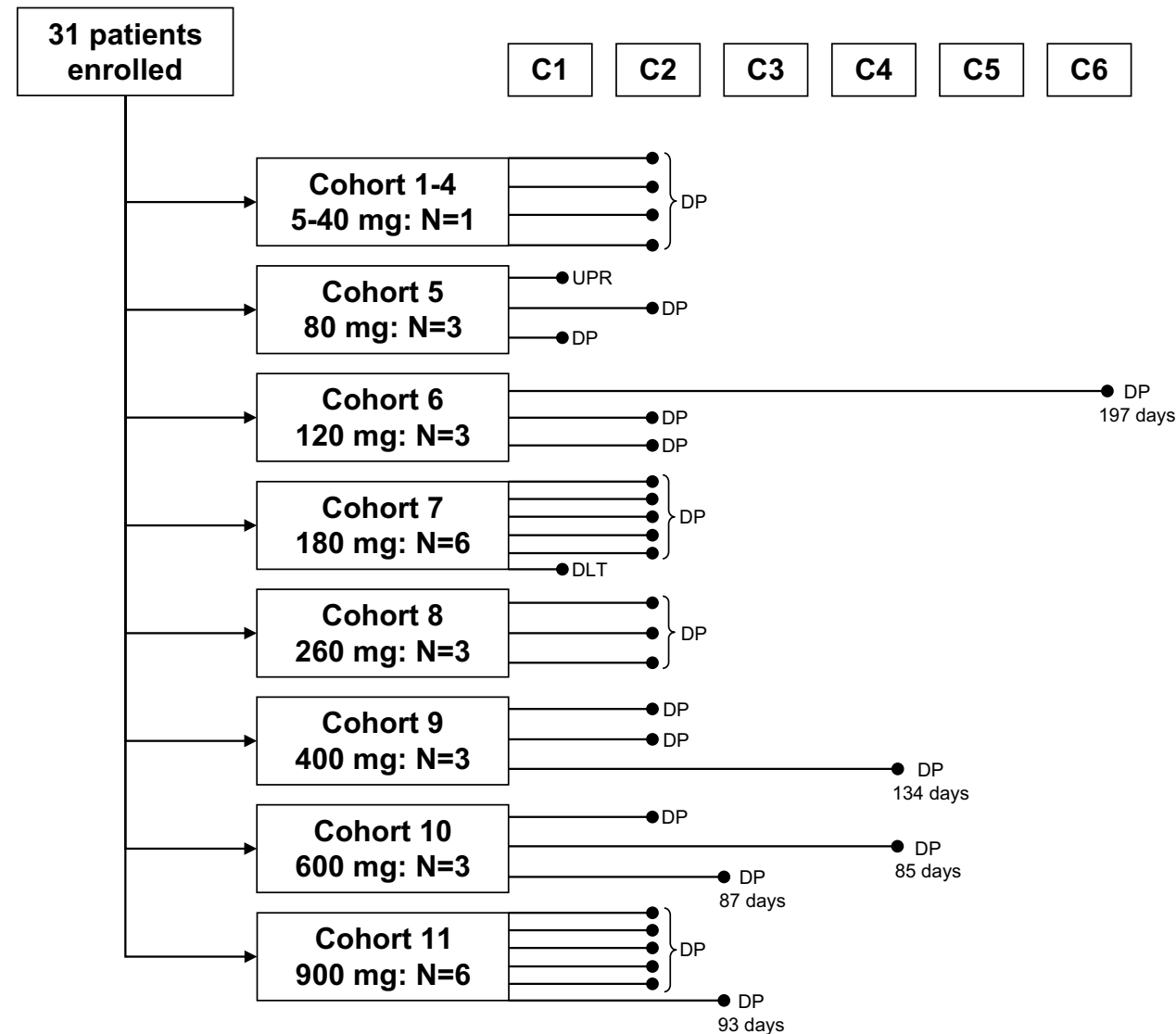

one American Indian, one Asian, and two African-American) with metastatic solid tumors except one lymphoma patient. Most common were colorectal cancer in 14 patients (45.1\%), melanoma in three (9.7\%), and NSCLC in two $(6.5 \%)$; remaining tumor entities $(38.7 \%)$ were represented by one patient only (adrenal, angiosarcoma, appendiceal, breast, gastroesophageal, hemangiopericytoma, Hurthle cell, myoepithelial, ovarian, salivary gland, SCC penis).

Patients were treated with DEBIO1143 for up to 117 days and all patients completed at least one cycle; 2 cycles: 27 (87.1\%) patients; 3 and 4 cycles: 5 (16.1\%) patients each; 5 and 6 cycles: $2(6.5 \%)$ patients each; 7 and 8 cycles: one patient each (3.2\%) (Fig. 1; median 2 cycles). A drug-related grade 2 fatigue in a patient treated with $80 \mathrm{mg}$ prompted expansion to 3-patient cohorts. Subsequently, a grade 3 reversible ALT elevation in a patient receiving $180 \mathrm{mg}$ was the only reported DLT which resulted in the expansion of this cohort to six patients. Dose was escalated to $900 \mathrm{mg}$ daily before enrollment was halted due to the excessive number of pills to be taken. Thus, the MTD was not reached.

Safety

Of 31 patients in the safety population, 30 (96.8\%) experienced 242 AEs of which 82 (33.9\%) were considered related to study drug (ADRs). Most AEs were of mild to moderate severity and neither incidence nor severity increased with dose. The most affected organ systems were gastrointestinal, general, and skin and subcutaneous disorders (Table 1) with fatigue, nausea, and vomiting as the most common treatment-related AE, each occurring in $>10 \%$ of patients (Suppl. 1). A total of eight patients (25.8\%) experienced 13 SAEs (constipation, intestinal obstruction, asthenia, pain, cerebrovascular accident, cranial nerve disorder, urinary retention (once each); nausea, vomiting, dyspnoea (twice each)), none of which was considered related to study drug. No patient died during the study. Four (12.9\%) patients discontinued drug treatment due to AEs (ALT increase, cranial nerve disorder, abdominal pain, dyspnoea), of which only the ALT increase was considered related to study drug. This DLT was a fivefold, but asymptomatic ALT increase along with grade 2 elevations of other liver function tests after the first treatment cycle in a 57-year-old white female patient with metastatic colon cancer. ALT but not the other liver function tests had considerably decreased 30 days posttreatment although metastatic disease in the liver may have been a contributing factor. ALT, AST, and GGT were within normal ranges in all remaining patients.

No clinically meaningful trends were seen in measurements of safety laboratory, ECG, vital signs, body weight, 
Table 1 Number of patients with ADRs and ADR frequency by system organ class

\begin{tabular}{|c|c|c|c|c|c|c|c|c|c|c|}
\hline $\begin{array}{l}\text { Dose cohort } \\
N\end{array}$ & $\begin{array}{l}\leq 40 \mathrm{mg} \\
4\end{array}$ & $80 \mathrm{mg}$ & $120 \mathrm{mg}$ & $180 \mathrm{mg}$ & $260 \mathrm{mg}$ & $400 \mathrm{mg}$ & $600 \mathrm{mg}$ & $900 \mathrm{mg}$ & Total & $\begin{array}{l}\% \\
100\end{array}$ \\
\hline Gastrointestinal disorders & 1 & 2 & 1 & 2 & 1 & 1 & 2 & 3 & 13 & 41.9 \\
\hline General disorders and administration site reactions & 1 & 2 & & 3 & & 1 & 2 & 1 & 10 & 32.3 \\
\hline Skin and subcutaneous disorders & & 1 & 1 & 2 & & 1 & 1 & 3 & 9 & 29.0 \\
\hline Metabolism and nutrition disorders & 1 & & & 1 & & 1 & 1 & 2 & 6 & 19.4 \\
\hline Musculoskeletal and connective tissue disorders & 1 & 1 & & & & 1 & 1 & & 4 & 12.9 \\
\hline Nervous system disorders & & & & 1 & & 1 & & 1 & 3 & 9.7 \\
\hline Investigations & & & & 3 & & & & & 3 & 9.7 \\
\hline Respiratory, thorax, and mediastinum disorders & 1 & & & & & & 1 & & 2 & 6.5 \\
\hline Eye disorders & & & & 1 & & & & & 1 & 3.2 \\
\hline Psychiatric disorders & & 1 & & & & & & & 1 & 3.2 \\
\hline Vascular disorders & 1 & & & & & & & & 1 & 3.2 \\
\hline Patients with any related $\mathrm{AE}$ & 1 & 2 & 1 & 5 & 1 & 1 & 3 & 4 & 18 & 58.1 \\
\hline
\end{tabular}

or ECOG performance status. There were no dose reductions, delays, or modifications due to AEs or lack of tolerability.

\section{Pharmacokinetics}

DEBIO1143 drug levels at doses of $\geq 80 \mathrm{mg}$ exceeded levels that have demonstrated activity in animal models. DEBIO1143 showed rapid absorption after oral intake with peak plasma concentrations within 1-3 h. Overall, increases in $C_{\max }$ and AUC were proportional to doses $\geq 80 \mathrm{mg}$ (Fig. 2). In general, PK disposition varied among individuals (Table 2), but mean $T_{1 / 2}$ of DEBIO1143 on day 1 was consistent [5.2-7.1 h] regardless of the dose. No evidence of drug accumulation was observed over the 5-day dosing period.

Pharmacodynamics

\section{cIAP1 levels in tissues and PBMCs}

A rapid and substantial cIAP1 degradation was observed in tumor or surrogate tissues. IHC staining of cIAP1 in skin biopsies of 12 patients revealed a trend for a decrease in the level of cIAP1 (Fig. 3a). In baseline and on-treatment tumor biopsies from two patients with melanoma, cIAP1 was detected with intensities ranging from 0 to $2+$. In the patient treated with DEBIO1143 at $120 \mathrm{mg} /$ day, the immunoactivity of cIAP1 decreased from 150 (predose) to 130 on day 5. By contrast, only negligible effect on the percentage of cIAP1-positive cells was observed in the tumor biopsies of the other melanoma patient treated at $400 \mathrm{mg} / \mathrm{d}$.

The expression of cIAP1 was evaluable in PBMCs from 28 patients with doses above $80 \mathrm{mg}$ using Western
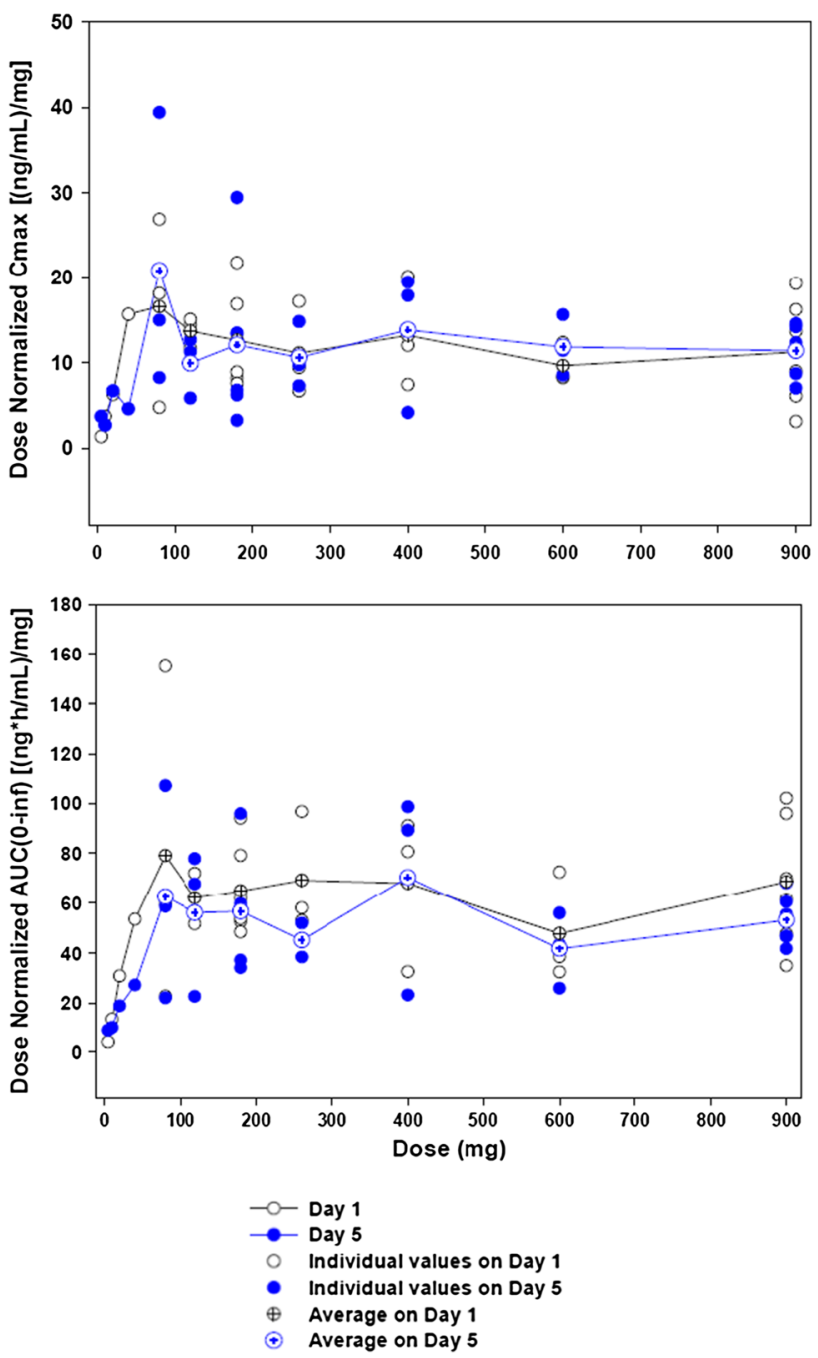

Fig. 2 Dose proportionality of $C_{\max }$ and $\mathrm{AUC}_{\text {inf }}$ 
Table 2 Pharmacokinetics of DEBIO1143, means (standard deviation)

\begin{tabular}{|c|c|c|c|c|c|c|c|c|c|c|c|c|}
\hline \multirow{2}{*}{$\begin{array}{l}\text { Dose } \\
(\mathrm{mg})\end{array}$} & \multirow[t]{2}{*}{$n$} & \multicolumn{2}{|c|}{$C_{\max }(\mathrm{ng} / \mathrm{mL})$} & \multicolumn{2}{|c|}{$T_{\max } * *(\mathrm{~h})$} & \multicolumn{2}{|c|}{$\mathrm{AUC}_{0-\mathrm{t}}(\mathrm{ng} * \mathrm{~h} / \mathrm{mL})$} & \multicolumn{2}{|c|}{$\mathrm{AUC}_{0-\text { inf }}(\mathrm{ng} * \mathrm{~h} / \mathrm{mL})$} & \multicolumn{2}{|l|}{$T_{1 / 2}(\mathrm{~h})$} & \multirow{2}{*}{$\begin{array}{l}\text { Day 1:5 } \\
\text { ratio }\end{array}$} \\
\hline & & Day 1 & Day 5 & Day 1 & Day 5 & Day 1 & Day 5 & Day 1 & Day 5 & Day 1 & Day 5 & \\
\hline 5 & 1 & 6.69 & 18.5 & 3.0 & 1.6 & 19.6 & 43.4 & ND & ND & ND & ND & ND \\
\hline 10 & 1 & 37.4 & 26.9 & 1.0 & 3.5 & 129 & 103 & 152 & 117 & 2.46 & 2.53 & 0.77 \\
\hline 20 & 1 & 126 & 134 & 1.0 & 0.5 & 615 & 375 & 643 & 451 & 5.44 & 3.37 & 0.70 \\
\hline 40 & 1 & 627 & 184 & 1.0 & 6.1 & 2140 & 1090 & 2300 & ND & 6.38 & ND & ND \\
\hline 80 & 3 & $\begin{array}{l}1330 \\
(891)\end{array}$ & $\begin{array}{l}1670 \\
(1310)\end{array}$ & $\begin{array}{l}2.0 \\
(0.7-3.0)\end{array}$ & $\begin{array}{l}2.0 \\
(0.6-2.0)\end{array}$ & $\begin{array}{l}6390 \\
(5420)\end{array}$ & $\begin{array}{l}5020 \\
(3450)\end{array}$ & $\begin{array}{l}6660 \\
(5700)\end{array}$ & $\begin{array}{l}5920 \\
(4270)\end{array}$ & $\begin{array}{l}5.22 \\
\quad(0.890)\end{array}$ & $\begin{array}{l}2.69 \\
\quad(0.593)\end{array}$ & $0.96(0.13)$ \\
\hline 120 & 3 & $\begin{array}{l}1650 \\
(217)\end{array}$ & $\begin{array}{l}1190 \\
(432)\end{array}$ & $\begin{array}{l}1.0 \\
(0.5-1.0)\end{array}$ & $\begin{array}{l}2.0 \\
(1.0-3.0)\end{array}$ & $\begin{array}{l}6890 \\
(1010)\end{array}$ & $\begin{array}{l}5430 \\
(2570)\end{array}$ & $\begin{array}{l}7460 \\
(1230)\end{array}$ & $\begin{array}{l}6770 \\
(3460)\end{array}$ & $\begin{array}{l}6.39 \\
(1.04)\end{array}$ & $\begin{array}{l}2.61 \\
(0.505)\end{array}$ & $0.88(0.36)$ \\
\hline 180 & 7 & $\begin{array}{l}2130 \\
(1010)\end{array}$ & $\begin{array}{l}2160 \\
(1550)\end{array}$ & $\begin{array}{l}2.0 \\
(0.5-6.0)\end{array}$ & $\begin{array}{l}2.0 \\
(0.5-6.0)\end{array}$ & $\begin{array}{l}10,600 \\
(2990)\end{array}$ & $\begin{array}{l}7210 \\
(3620)\end{array}$ & $\begin{array}{c}11,400 \\
(3080)\end{array}$ & $\begin{array}{l}9980 \\
\quad(5150)\end{array}$ & $\begin{array}{l}6.06 \\
(1.05)\end{array}$ & $\begin{array}{l}4.14 \\
\quad(1.72)\end{array}$ & $0.90(0.45)$ \\
\hline 260 & 3 & $\begin{array}{l}2890 \\
(1420)\end{array}$ & $\begin{array}{l}2760 \\
(999)\end{array}$ & $\begin{array}{l}3.0 \\
(1.0-3.0)\end{array}$ & $\begin{array}{l}2.0 \\
(1.1-6.0)\end{array}$ & $\begin{array}{l}16,300 \\
(5710)\end{array}$ & $\begin{array}{l}10600 \\
(2910)\end{array}$ & $\begin{array}{r}17,900 \\
(6260)\end{array}$ & $\begin{array}{c}11,700 \\
(2520)\end{array}$ & $\begin{array}{l}6.59 \\
(0.416)\end{array}$ & $\begin{array}{l}3.29 \\
(0.573)\end{array}$ & $0.82(0.14)$ \\
\hline 400 & 3 & $\begin{array}{l}5280 \\
(2570)\end{array}$ & $\begin{array}{l}5540 \\
(3370)\end{array}$ & $\begin{array}{l}1.0 \\
(0.6-2.0)\end{array}$ & $\begin{array}{l}0.5 \\
(0.5-2.0)\end{array}$ & $\begin{array}{l}25,000 \\
(11,300)\end{array}$ & $\begin{array}{l}20,100 \\
(11,700)\end{array}$ & $\begin{array}{l}27,000 \\
\quad(12,400)\end{array}$ & $\begin{array}{l}26,500 \\
(15,200)\end{array}$ & $\begin{array}{l}6.27 \\
\quad(0.367)\end{array}$ & $\begin{array}{l}3.70 \\
\quad(0.390)\end{array}$ & $0.92(0.19)$ \\
\hline 600 & 3 & $\begin{array}{l}5780 \\
(1410)\end{array}$ & $\begin{array}{l}7110 \\
(2140)\end{array}$ & $\begin{array}{l}1.1 \\
(0.6-1.1)\end{array}$ & $\begin{array}{l}1.0 \\
(0.5-1.1)\end{array}$ & $\begin{array}{l}27,000 \\
(12,500)\end{array}$ & $\begin{array}{l}20,200 \\
(7530)\end{array}$ & $\begin{array}{l}28,700 \\
(13,400)\end{array}$ & $\begin{array}{l}25,000 \\
(9090)\end{array}$ & $\begin{array}{l}5.75 \\
\quad(0.478)\end{array}$ & $\begin{array}{l}3.54 \\
(1.67)\end{array}$ & $0.90(0.21)$ \\
\hline 900 & 6 & $\begin{array}{l}10,100 \\
(5600)\end{array}$ & $\begin{array}{l}10,300 \\
(2710)\end{array}$ & $\begin{array}{l}1.5 \\
(1.0-3.0)\end{array}$ & $\begin{array}{l}1.5 \\
(1.0-3.0)\end{array}$ & $\begin{array}{l}56,100 \\
(21,900)\end{array}$ & $\begin{array}{l}36,900 \\
(8210)\end{array}$ & $\begin{array}{l}61,500 \\
(23,500)\end{array}$ & $\begin{array}{l}47,000 \\
(8550)\end{array}$ & $\begin{array}{l}7.11 \\
\quad(0.675)\end{array}$ & $\begin{array}{l}3.15 \\
\quad(0.408)\end{array}$ & $0.83(0.25)$ \\
\hline
\end{tabular}

$N D$ not determined

** Median (minimum-maximum)

Fig. 3 Expression of cIAP. a in skin biopsies of 12 patients ( $\mathrm{H}$-scores; on the top). $\mathbf{b}$ in PBMC (quantitative Western blot results as \% from baseline) across doses (on the bottom; for results per dose see Suppl. 2)
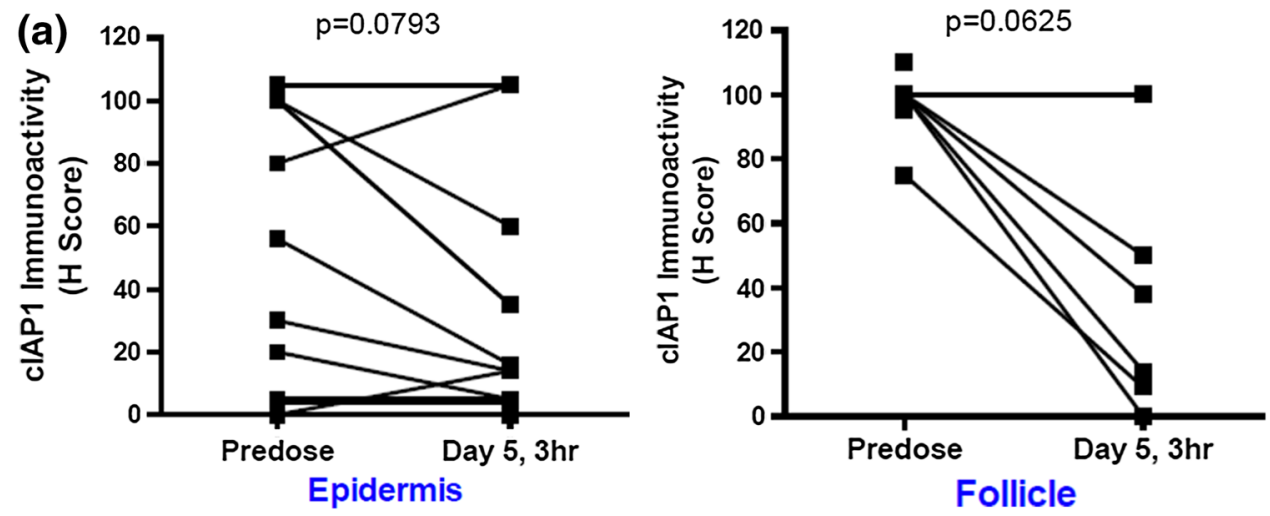
blot (Fig. 3b; Suppl. 2). In 20 patients, cIAP1 was readily detectable at baseline but undetectable or extremely low in eight patients. In all patients with detectable cIAP1, DEBIO1143 led to rapid and persistent cIAP1 degradation regardless of dose.

\section{Plasma levels of TNF $\alpha, I L 8, C C L 2$, and M30/M65}

In total, 173 plasma samples from 25 patients were measured for TNFa, CCL2, and IL8, biomarkers mechanistically related to DEBIO1143. In 108 samples, TNF $\alpha$ was below the limit of detection; four out of five patients with detectable $\mathrm{TNF} \alpha$ levels showed some increase postdose. CCL2 was detectable in 25 patients and increased in 14 patients across all dose levels; however, CCL2 increased in five out of six patients dosed with $900 \mathrm{mg}$ (mean increase $45 \%$, range -6 to $54 \%$ ). Increases became significant 3 and $6 \mathrm{~h}$ postdose $(p<0.0001$, Fig. 4$)$. By contrast, neither an increase in plasma IL8 nor any correlation with DEBIO1143 exposure was observed. Plasma level of M30 increased significantly on day 5 ( $p<0.0033$; Fig. 4). However, no significant changes were found for M65 or for the M30:M65 ratio. None of the biomarkers showed any apparent relationship to the treatment response.

\section{Antitumor activity}

No patient had a complete or partial response. One patient with metastatic melanoma with latero-cervical lymph node involvement showed an $11 \%$ reduction in target lesion dimensions at $400 \mathrm{mg} /$ day. Progression in the same nodes was noted after six cycles. Stable disease as best response was seen in five patients $(16.1 \%)$ for a median duration of 93 days (range 85-197 days; Fig. 1). All these patients had different cancer types (Hurthle cell, melanoma, breast, rectal, hemangiopericytoma).

\section{Discussion}

Several SMAC mimetic IAP antagonists have entered clinical development, including DEBIO1143 (formerly AT-406), HGS1029 (formerly AEG-40826), GDC-0917 and -0152, LCL-161, and birinapant (TL-32711). The latter two compounds have entered phase II trials. Our results on DEBIO1143 add to the existing body of evidence from these clinical trials on SMAC mimetic IAP antagonists. In general, tolerability and safety of this class of drugs have been acceptable [12-14]. These trials have not revealed any consistent AE in humans [3, 12-14] except an increased incidence of Bell's Palsy syndrome at higher doses of birinapant which can be prevented by dose titration in the initial treatment cycle [15]. In this regard, it is noteworthy
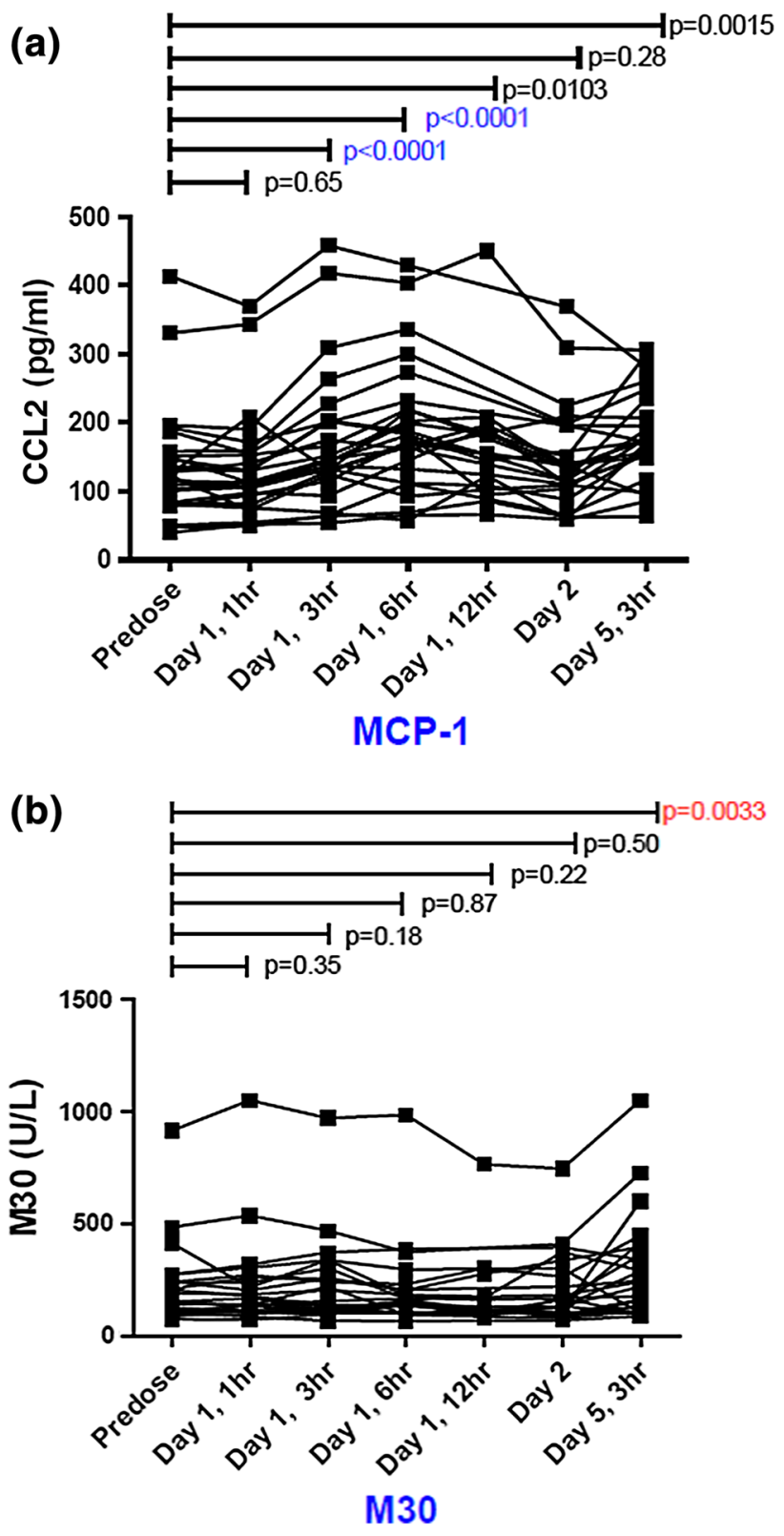

Fig. 4 Pharmacodynamic measurements

that the cerebrovascular accident and cranial nerve disorder in our study were both unlikely related to DEBIO1143. The former occurred 23 days after last intake, and signs of thrombocytopenia, coagulopathy, or hypertension were absent during the two cycles of treatment as well as at the time of the event. By contrast, an occult metastasis could not be ruled out. The cranial nerve disorder was not Bell's Palsy syndrome as it affected cranial nerve 5 rather than 7 ; it was most consistent with progression of leptomeningeal disease. In general, there was no grade 4-5 treatmentrelated $\mathrm{AE}$ at all, even during treatment for over 6 months. The only case of transient G3 hepatotoxicity is consistent 
with preclinical data and linked to the mechanism of action of SMAC mimetic IAP inhibitors [16, 17].

Our PK data in humans confirmed drug exposures at or above those needed for activity in preclinical models [7]. PK disposition of DEBIO1143 is suitable for once daily dosing over 5 consecutive days every 3 weeks. DEBIO1143 showed proportional plasma increases at doses $>80 \mathrm{mg}$ in our study (Fig. 2). However, beyond this threshold, neither PD nor antitumor activity showed any dose relationship, but all doses resulted in the degradation of cIAP-1 in PBMCs and at least in a trend for a decrease in cIAP levels in surrogate skin tissue. The on-target activity of DEBIO1143 was also supported by the significant increase in CCL2 plasma levels (Fig. 4), which might be a consequence of the cIAP-1 degradation through modulation of NF-кB. CCL2, actually a marker of inflammation, has also been associated with the stimulation of a host antitumor response [18] which would be in line with the observed M30 increase indicating druginduced epithelial apoptosis [19].

However, interpretation of PD data remains limited due to the small samples sizes of dose groups and the lacking dose-response relationship. Our data also remain inconclusive regarding a recommendable dose, although $900 \mathrm{mg} /$ day resulted in acceptable tolerability and in exposures with proven activity in preclinical experiments. It may thus serve at least as a starting dose for phase II. In addition, the modest clinical activity of IAP inhibitors shown in unselected refractory cancer patients so far suggests the need for combination approaches and screening for more sensitive subpopulations.

Acknowledgments Authors would like to thank patients and their families and caregivers, the clinical research nurses and physicians at Duke University Medical Center, University of Michigan, and the Mayo Clinic who helped in the management of the patients on this study, and Uwe Totzke for medical writing support sponsored by Debiopharm SA, Lausanne. This work was supported by Ascenta Therapeutics, Malvern, PA, USA.

Conflict of interest GV, ER, and CZ are employed by Debiopharm International SA; JMB was an employee of Ascenta Therapeutics at the time of the study and has vested stock options which have not yet been exercised. JMS was President and CEO of Ascenta Therapeutics. He holds stocks and still acts as CEO on a consultant basis. HIH, DCS, and HCP did not declare any potential conflict of interest.

Open Access This article is distributed under the terms of the Creative Commons Attribution License which permits any use, distribution, and reproduction in any medium, provided the original author(s) and the source are credited.

\section{References}

1. Zhang T, Li Y, Zou P, Yu JY, McEachern D, Wang S, Sun D (2013) Physiologically based pharmacokinetic and pharmacodynamic modeling of an antagonist (SM-406/AT-406) of multiple inhibitor of apoptosis proteins (IAPs) in a mouse xenograft model of human breast cancer. Biopharm Drug Dispos 34(6):348-359. doi: $10.1002 /$ bdd. 1850

2. Miura K, Fujibuchi W, Ishida K, Naitoh T, Ogawa H, Ando T, Yazaki N, Watanabe K, Haneda S, Shibata C, Sasaki I (2011) Inhibitor of apoptosis protein family as diagnostic markers and therapeutic targets of colorectal cancer. Surg Today 41(2):175182. doi:10.1007/s00595-010-4390-1

3. Dubrez L, Berthelet J, Glorian V (2013) IAP proteins as targets for drug development in oncology. OncoTargets Ther 9:12851304. doi: $10.2147 /$ ott.s33375

4. Brunckhorst MK, Lerner D, Wang S, Yu Q (2012) AT-406, an orally active antagonist of multiple inhibitor of apoptosis proteins, inhibits progression of human ovarian cancer. Cancer Biol Ther 13(9):804-811. doi:10.4161/cbt.20563

5. Fulda $S$ (2007) Inhibitor of apoptosis proteins as targets for anticancer therapy. Expert Rev Anticancer Ther 7(9):1255-1264. doi:10.1586/14737140.7.9.1255

6. Fulda S (2013) Molecular pathways: targeting inhibitor of apoptosis proteins in cancer-from molecular mechanism to therapeutic application. Clin Cancer Res. doi:10.1158/1078-0432. ccr-13-0227

7. Cai Q, Sun H, Peng Y, Lu J, Nikolovska-Coleska Z, McEachern D, Liu L, Qiu S, Yang CY, Miller R, Yi H, Zhang T, Sun D, Kang S, Guo M, Leopold L, Yang D, Wang S (2011) A potent and orally active antagonist (SM-406/AT-406) of multiple inhibitor of apoptosis proteins (IAPs) in clinical development for cancer treatment. J Med Chem 54(8):2714-2726. doi:10.1021/jm101505d

8. Viert D, Rigotti S, Kadi L, Zanna C, Vuagniaux G, Matzinger O, Vozenin MC, Bourhis J (2014) Debio 1143, an oral antagonist of the inhibitor of apoptosis proteins (IAPs) sensitises multiple SCCHN models to radiotherapy. In: Paper presented at the European congress on head and neck oncology (ECHNO), Liverpool, UK, pp 24-26

9. Wong H, Budha NR, West K, Blackwood E, Ware JA, Yu R, Darbonne WC, Gould SE, Steigerwalt R, Erickson R, Hop CE, LoRusso P, Eckhardt SG, Wagner A, Chan IT, Mamounas M, Flygare JA, Fairbrother WJ (2012) Dogs are more sensitive to antagonists of inhibitor of apoptosis proteins than rats and humans: a translational toxicokinetic/toxicodynamic analysis. Toxicol Sci 130(1):205-213. doi:10.1093/toxsci/kfs235

10. Eisenhauer EA, Therasse P, Bogaerts J, Schwartz LH, Sargent D, Ford R, Dancey J, Arbuck S, Gwyther S, Mooney M, Rubinstein L, Shankar L, Dodd L, Kaplan R, Lacombe D, Verweij J (2009) New response evaluation criteria in solid tumours: revised RECIST guideline (version 1.1). Eur J Cancer 45(2):228-247. doi:10.1016/j.ejca.2008.10.026

11. Cheson BD, Pfistner B, Juweid ME, Gascoyne RD, Specht L, Horning SJ, Coiffier B, Fisher RI, Hagenbeek A, Zucca E, Rosen ST, Stroobants S, Lister TA, Hoppe RT, Dreyling M, Tobinai K, Vose JM, Connors JM, Federico M, Diehl V, International Harmonization Project on L (2007) Revised response criteria for malignant lymphoma. J Clin Oncol 25(5):579-586. doi:10.1200/ JCO.2006.09.2403

12. Sikic BI, Eckhardt SG, Gallant G, Burris HA, Camidge DR, Colevas AD, Jones SF, Messersmith WA, Wakelee HA, Li H, Kaminker PG, Morris S, Infante JR (2011) Safety, pharmacokinetics (PK), and pharmacodynamics (PD) of HGS1029, an inhibitor of apoptosis protein (IAP) inhibitor, in patients (Pts) with advanced solid tumors: results of a phase I study. J Clin Oncol 29 (suppl;):abstr 3008

13. Tolcher AW, Papadopoulos KP, Patnaik A, Fairbrother WJ, Wong H, Budha NR, Darbonne WC, Peale FV, Mamounas MJ, Royer-Joo S, Yu R, Portera CC, Bendell JC, Burris HA, Infante JR (2013) Phase I study of safety and pharmacokinetics (PK) of GDC-0917, an antagonist of inhibitor of apoptosis (IAP) proteins 
in patients (Pts) with refractory solid tumors or lymphoma. J Clin Oncol 31(suppl):abstr 2503

14. Amaravadi RK, Schilder RJ, Dy GK, Ma WW, Fetterly GJ, Weng DE, Graham MA, Burns JM, Chunduru SK, Condon SM, McKinlay MA, Adjei AA (2011) Phase 1 study of the smac mimetic TL32711 in adult subjects with advanced solid tumors and lymphoma to evaluate safety, pharmacokinetics, pharmacodynamics, and antitumor activity. Cancer Res 71(8(suppl 1)):LB406. doi:10.1158/1538-7445.AM2011-LB-406

15. Amaravadi RK, Senzer NN, Martin LP, Schilder RJ, LoRusso P, Papadopoulos KP, Weng DE, Graham M, Adjei AA (2013) A phase I study of birinapant (TL32711) combined with multiple chemotherapies evaluating tolerability and clinical activity for solid tumor patients. J Clin Oncol 31(suppl):abstr 2504

16. Erickson RI, Tarrant J, Cain G, Lewin-Koh SC, Dybdal N, Wong H, Blackwood E, West K, Steigerwalt R, Mamounas M, Flygare
JA, Amemiya K, Dambach D, Fairbrother WJ, Diaz D (2013) Toxicity profile of small-molecule IAP antagonist GDC-0152 is linked to TNF-alpha pharmacology. Toxicol Sci 131(1):247-258. doi:10.1093/toxsci/kfs265

17. Akazawa Y, Guicciardi ME, Cazanave SC, Bronk SF, Werneburg NW, Kakisaka K, Nakao K, Gores GJ (2013) Degradation of cIAPs contributes to hepatocyte lipoapoptosis. Am J Physiol Gastrointest Liver Physiol 305(9):G611-G619. doi:10.1152/ ajpgi.00111.2013

18. Deshmane SL, Kremlev S, Amini S, Sawaya BE (2009) Monocyte chemoattractant protein-1 (MCP-1): an overview. J Interf Cytokine Res 29(6):313-326. doi:10.1089/jir.2008.0027

19. Linder S, Olofsson MH, Herrmann R, Ulukaya E (2010) Utilization of cytokeratin-based biomarkers for pharmacodynamic studies. Expert Rev Mol Diagn 10(3):353-359. doi:10.1586/ erm. 10.14 